\title{
Avaliação in vitro da atividade antibacteriana da água ozonizada frente ao Staphylococcus aureus
}

\section{In vitro evaluation of the antibacterial activity of ozonized water against Staphylococcus aureus}

\author{
Helena Engel VELANO* \\ Luiz Carlos do NASCIMENTO** \\ Letízia Monteiro de BARROS* \\ Heitor PANZERI***
}

\begin{abstract}
VELANO, H. E.; NASCIMENTO, L. C. do; BARROS, L. M. de; PANZERI, H. Avaliação in vitro da atividade antibacteriana da água ozonizada frente ao Staphylococcus aureus. Pesqui Odontol Bras, v. 15, n. 1, p. 18-22, jan./mar. 2001.

O Staphylococcus aureus faz parte da microbiota da pele, mucosas e nasofaringe de várias espécies animais, incluindo o homem, mas também está associado a enfermidades como abscessos, bacteremias, endocardites e osteomielites, além de se mostrar resistente a múltiplas drogas. Este trabalho foi realizado com a finalidade de avaliar o efeito do gás ozônio, dissolvido em água, sobre o S. aureus. Foram preparadas suspensões de S. aureus, com concentrações variando de $10^{6}$ a $10^{16}$ microrganismos $/ \mathrm{ml}$. De cada suspensão recém-preparada foi retirado $1 \mathrm{ml}$ e adicionado a $99 \mathrm{ml}$ de água destilada estéril (com ou sem prévia ozonização), em um reator de cristal. Foram preparadas diluições seriadas $(1 / 10)$ das suspensões testadas e inoculado $0,1 \mathrm{ml}$ de cada suspensão em Tryptic Soy Agar, incubadas a $37^{\circ} \mathrm{C}$ por $24 \mathrm{~h}$, quando então se procedeu à contagem das UFC. Os resultados obtidos mostraram que o tempo máximo para a inativação total das bactérias tratadas com água previamente ozonizada $(0,6 \mathrm{mg} / \mathrm{ml})$ foi de 5 '25" e, para a água não previamente ozonizada, foi de 23'45”, indicando um efeito antibacteriano mais rápido da água previamente ozonizada, frente ao $S$. aureus.
\end{abstract}

UNITERMOS: Ozônio; Staphylococcus aureus; Água; Desinfecção.

\section{INTRODUÇÃO}

Uma parte importante da literatura odontológica tem se dedicado, atualmente, aos riscos ocupacionais aos quais os cirurgiões-dentistas, seus auxiliares e pacientes estão expostos. A ocorrência de doenças infecto-contagiosas no ambiente profissional tem sido reconhecida há muito tempo, mas somente após a descoberta do vírus HIV e das suas formas de transmissão é que um maior enfoque foi dado para o controle de infecções na prática odontológica (CRAWFORD ${ }^{6}$, 1985; HAZELKORN et al. ${ }^{13}$, 1996; EDMUNDS et al. $\left.{ }^{10}, 1998\right)$. Vários microrganismos orais, como estreptococos e estafilococos, são potencialmente patogênicos e podem causar sérias infecções, especialmente em indivíduos imunocomprometidos (NEIDLE; YAGIELA ${ }^{18}, 1991$; MEURMAN et al. $\left.{ }^{16}, 1997\right)$. Assim, o controle de patógenos vem se tornando uma preocupação constante das ciências médicas e biológicas. Em Odon- tologia, tem-se procurado minimizar o risco de transmissão de microrganismos provenientes dos sistemas de água das unidades dentais, que são locais propícios ao desenvolvimento de populações microbianas (WILLIAMS et $a .^{22}$, 1994; ATLAS et $\left.a l .{ }^{1}, 1995\right)$. Muitas espécies de microrganismos vivem em comunidades complexas denominadas biofilmes, que se formam sobre uma variedade de superficies, como por exemplo as tubulações dos sistemas de condução de água (PREVOST et al. ${ }^{19}$, 1995; WINPENNY ${ }^{23}$, 1997). Bactérias tais como $P$. aeruginosa e $S$. aureus, de nutrição pouco exigente, são freqüentemente encontradas nos encanamentos e conexões de plástico, pois este material fornece uma fonte de carbono para o seu metabolismo, favorecendo a formação de uma cobertura lodosa, o que dificulta a ação dos desinfetantes $\left(\mathrm{BECK}^{2}, 1995\right)$.

Embora no início, o gás ozônio $\left(\mathrm{O}_{3}\right)$ tenha sido

\footnotetext{
* Professoras Mestras do Instituto de Odontologia e Ciências da Saúde da Universidade de Alfenas.

** Professor Mestre do Instituto de Odontologia e Farmácia da Universidade de Alfenas, Campus Varginha.

*** Professor Titular da Faculdade de Odontologia de Riberão Preto da Universidade de São Paulo.
} 
VELANO, H. E.; NASCIMENTO, L. C. do; BARROS, L. M. de; PANZERI, H. Avaliação in vitro da atividade antibacteriana da água ozonizada frente ao Staphylococcus aureus. Pesqui Odontol Bras, v. 15, n. 1, p. 18-22, jan./mar. 2001.

utilizado com a finalidade de desinfecção da água, outras funções foram-lhe atribuidas (VOSMAER ${ }^{21}$, 1916), como redução de cor, odor e sabor; potente oxidação de compostos orgânicos e inorgânicos e como precipitante de metais pesados. Tem sido considerado também um microbicida eficaz, agindo sobre vírus, fungos e bactérias. Supõe-se que o ataque primário do ozônio se dê sobre a parede celular da bactéria e, depois, ao penetrar no interior da célula, este agente promove a oxidação dos aminoácidos e ácidos nucléicos. A lise celular depende da extensão destas reações (GURLEY ${ }^{12}$, 1985). Como o ozônio tem sido utilizado, há mais de 80 anos, no tratamento da água potável em vários países da Europa, e por mostrar eficácia no tratamento da água de uso hospitalar, assim como nas unidades dos equipamentos odontológicos (DIAZ et $\left.a .^{7}, 1995\right)$, o objetivo do presente trabalho foi testar o efeito deste gás, dissolvido em água, sobre os Staphylococcus aureus.

\section{MATERIAL E MÉTODOS Produção da água ozonizada}

O conjunto elaborado para obter-se água ozonizada nas concentrações necessárias, constitui-se de:

- cilindro de oxigênio/válvulas redutoras com manômetros;

- gerador de ozônio (Ozone, mod. EAS 30 - UV), com capacidade de produção de $0,5 \mathrm{~g} / \mathrm{h}$ $\left(0,25 \%, p / p\right.$, na mistura $\left.\mathrm{O}_{2} / \mathrm{O}_{3}\right)$. O ozônio, neste sistema, foi gerado pela ação dos raios ultravioleta sobre as moléculas de oxigênio de alta pureza;

- reator de cristal com capacidade de $100 \mathrm{ml}$, acoplado ao gerador de ozônio formando um sistema de difusão de bolhas finas.

Para produção da água ozonizada, foi colocado o volume de $100 \mathrm{ml}$ de água destilada autoclavada no reator de cristal, onde se borbulhava a mistura $\mathrm{O}_{2} / \mathrm{O}_{3}$.

\section{Limpeza e esterilização do sistema de ozonização}

Para assegurar a esterilização e limpeza do sistema, ozonizou-se o volume de $100 \mathrm{ml}$ de água destilada autoclavada contida no reator de cristal, por 20 minutos. Após este tempo, esta água foi desprezada e igual volume foi recolocado para dar início ao experimento.

\section{Obtenção das suspensões bacterianas}

Foram utilizadas cepas de Staphylococcus aureus cedidas pelo Laboratório de Microbiologia da
Escola de Farmácia e Odontologia de Alfenas. Com estas bactérias na fase logarítmica, foram preparadas suspensões, em solução salina, cujas concentrações variavam de $10^{6}$ a $10^{16}$ microrganis$\mathrm{mos} / \mathrm{ml}$. Para a obtenção desta contagem inicial de microrganismos, as suspensões foram submetidas a diluições seriadas.

\section{Experimentos}

Foram realizados em dois grupos, colocando-se em contato suspensões bacterianas com:

- Grupo I - água destilada previamente ozonizada a uma concentração inicial de $0,6 \mathrm{mg} / 1$;

- Grupo II - água destilada sem prévia ozonização.

Nos experimentos do Grupo I, após a limpeza e a esterilização do sistema de difusão de bolhas finas, colocou-se $99 \mathrm{ml}$ de água destilada estéril, no reator de cristal e o sistema foi acionado, ozonizando-se esta água por 20 minutos, obtendo-se, assim, a saturação de $0,6 \mathrm{mg} / 1$. Após este periodo, foi adicionado, à água ozonizada no reator, $1 \mathrm{ml}$ da suspensão de Staphylococcus aureus, recém-preparada, cronometrando-se e mantendo-se o fluxo de ozônio constante até o término do experimento. Imediatamente, amostras em triplicatas de $0,1 \mathrm{ml}$ foram retiradas do centro do reator, submetidas a diluições seriadas e inoculadas em Tryptic Soy Agar (TSA, BBL) para a determinação da quantidade de microrganismos, neste intervalo de tempo. Novas amostras e suas diluições foram inoculadas com intervalos variados (devido às dificuldades técnicas de se padronizar os intervalos), a fim de determinar o tempo de morte de 99\% das bactérias. As placas inoculadas foram incubadas em estufa a $37^{\circ} \mathrm{C}$ e, após 24 horas, procedeu-se à contagem de UFC, determinando-se a concentração bacteriana em cada intervalo do experimento.

Para os experimentos do Grupo II, foi colocado, no reator, o volume de $99 \mathrm{ml}$ de água destilada estéril, adicionado de $1 \mathrm{ml}$ da suspensão bacteriana em teste. Após este procedimento, o sistema de ozonização e o cronômetro foram acionados simultaneamente. Foi mantido o fluxo constante de ozônio até o final dos experimentos. As etapas seguintes foram iguais às descritas para o Grupo I.

\section{RESULTADOS}

Foram realizados nove experimentos com suspensões de Staphylococcus aureus (Tabela 1), cujas concentrações variaram de $1,7 \times 10^{6}$ a $1,0 \times 10^{16}$, em água previamente ozonizada. Em todos eles, foi observada mais de $99 \%$ de morte bacteriana, já na primeira tomada de amostra da sus- 
VELANO, H. E.; NASCIMENTO, L. C. do; BARROS, L. M. de; PANZERI, H. Avaliação in vitro da atividade antibacteriana da água ozonizada frente ao Staphylococcus aureus. Pesqui Odontol Bras, v. 15, n. 1, p. 18-22, jan./mar. 2001.

pensão. Os tempos destas tomadas variaram de 4 segundos a 1 minuto e 52 segundos. A inativação bacteriana total, nestes experimentos foi conseguida com o tempo variando entre 4 segundos e $5 \mathrm{mi}-$ nutos e 25 segundos.

$\mathrm{Na}$ Tabela 2, observa-se que foram realizados quatro experimentos com suspensões de Staphylococcus aureus, cujas concentrações variaram de $1,7 \times 10^{6}$ a $2,6 \times 10^{10}$, em água sem prévia ozonização. A inativação total ocorreu no intervalo de 1 minuto e 31 segundos a 23 minutos e 45 segundos.

Os dados obtidos foram analisados estatisticamente através do teste $t$ de Student, com um nível de significância de $10 \%(\alpha=0,1)$. Os resultados mostraram que o tempo de inativação bacteriana foi menor no Grupo I, quando comparado ao Grupo II.

\section{DISCUSSÃO}

A Odontologia assumiu a responsabilidade de melhorar a qualidade dos cuidados odontológicos com os pacientes e, sendo assim, a adoção de uma metodologia para o controle de infecções é um exemplo importante da qualidade da prática profissional (COTTONE et al. $\left.{ }^{5}, 1996\right)$. Uma das formas de controle é por meio da utilização de agentes antibacterianos, como o ozônio, que, pelo seu amplo espectro de ação antimicrobiano e ainda por atuar

TABELA 1 - Tempo de inativação de Staphylococcus aureus pelo ozônio presente em água previamente tratada.

\begin{tabular}{|c|c|c|c|c|c|}
\hline \multirow{2}{*}{$\begin{array}{l}\text { Experi- } \\
\text { mento }\end{array}$} & \multirow{2}{*}{$\begin{array}{l}\text { Início } \\
\mathrm{N}^{\circ} \mathrm{de} \\
\text { cél./ml }\end{array}$} & \multicolumn{2}{|c|}{$1^{\mathrm{a}}$ tomada } & \multicolumn{2}{|c|}{$\begin{array}{c}\text { Final do } \\
\text { experimento }\end{array}$} \\
\hline & & Tempo & $\begin{array}{l}\mathrm{N}^{\mathrm{o}} \mathrm{de} \\
\text { cél./ml }\end{array}$ & Tempo & $\begin{array}{l}\mathrm{N}^{\mathrm{o}} \mathrm{de} \\
\text { cél./ml }\end{array}$ \\
\hline 1 & $3,0 \times 10^{10}$ & $32 "$ & $3,0 \times 10^{6}$ & $5,25^{\prime \prime}$ & 0 \\
\hline 2 & $2,6 \times 10^{12}$ & 1'52'" & $1,6 \times 10^{5}$ & - & - \\
\hline 3 & $1,4 \times 10^{13}$ & 1'14"' & $1,7 \times 10^{7}$ & - & - \\
\hline 4 & $3,5 \times 10^{12}$ & $28 "$ & 0 & $28 "$ & 0 \\
\hline 5 & $2,0 \times 10^{7}$ & $4 "$ & 0 & $4 "$ & 0 \\
\hline 6 & $1,0 \times 10^{16}$ & $6 "$ & 0 & 3'25' & 0 \\
\hline 7 & $1,0 \times 10^{8}$ & $30 "$ & $6,5 \times 10^{4}$ & 2'26”' & 0 \\
\hline 8 & $4,0 \times 10^{13}$ & $20 "$ & $6,0 \times 10^{3}$ & 2'29"' & 0 \\
\hline 9 & $1,7 \times 10^{6}$ & $40 "$ & 30 & 1'26" & 0 \\
\hline $\mathrm{x}$ & $1,12 \times 10^{15}$ & $38^{\prime} 44^{\prime \prime}$ & $5,48 \times 10^{5}$ & 1'45" & 0 \\
\hline $\begin{array}{l}\text { Desvio } \\
\text { padrão }\end{array}$ & $3,33 \times 10^{15}$ & $34 "$ & $1,07 \times 10^{6}$ & $1 ' 52 "$ & 0 \\
\hline
\end{tabular}

como agente "purificador" da água, pode auxiliar o processo de descontaminação do sistema de distribuição de água dos consultórios dentais (WILLIAMS et al. ${ }^{22}$, 1994; $\mathrm{BECK}^{2}$, 1995; RODRIGUES ${ }^{20}$, 1994), levando a um padrão aceitável de sua qualidade (GURLEY ${ }^{12}$, 1985; DOMINGUE ${ }^{9}, 1988$ ).

Os dados obtidos neste trabalho (Tabelas 1 e 2) demonstraram o efeito antibacteriano do ozônio sobre o $S$. aureus, mesmo em suspensões com elevada turbidez, uma vez que foram utilizadas suspensões cujas concentrações bacterianas eram, em sua maioria, superiores às de outros trabalhos, em que se utilizavam suspensões com concentrações variando de $10^{4}$ a $10^{8} \mathrm{UFC} / \mathrm{ml}$ (LEZCANO et al. ${ }^{14,15}$, 1997; FETNER; INGOLS ${ }^{11}$, 1959; BROADWATER et $\left.a l .{ }^{4}, 1973\right)$. De fato, estes mesmos autores obtiveram resultados semelhantes, mas com concentrações diferentes de ozônio. Para LEZCANO et al. ${ }^{14}$ (1997a), a variação de concentração de ozônio residual foi de 0,3 a 2,61 mg/1. GURLEY $^{12}$ (1985), trabalhando com $S$. aureus e outras espécies bacterianas, em suspensões contendo entre $10^{6}$ a $10^{7} \mathrm{UFC} / \mathrm{ml}$, com uma concentração de ozônio residual inicial de 0,3 a 1,5 mg/l, conseguiu inativação bacteriana total em 5 minutos. DICKERMAN et al. ${ }^{8}$ (1954) também obteve resultados semelhantes nestas mesmas condições. Entretanto, nos trabalhos citados, havia a aferição, a cada instante, do residual de ozônio presente na água, por meio de dispositivos ainda não disponíveis no Brasil. Por este motivo, estabeleceu-se, neste trabalho, a concentração de ozônio somente no início $(0,6 \mathrm{mg} / 1)$, pela impossibilidade da aferição no seu decorrer, mas é provável que houvesse um residual inferior a $0,6 \mathrm{mg} / 1$. Pode-se observar

TABELA 2 - Tempo de inativação de Staphylococcus aureus pelo ozônio presente em água não tratada previamente.

\begin{tabular}{c|c|c|c|c|c}
\hline \hline \multirow{2}{*}{$\begin{array}{c}\text { Experi- } \\
\text { mento }\end{array}$} & Início & \multicolumn{2}{|c|}{$1^{\text {a }}$ tomada } & \multicolumn{2}{c}{$\begin{array}{c}\text { Final do } \\
\text { experimento }\end{array}$} \\
\cline { 2 - 6 } & $\begin{array}{c}\mathrm{N}^{\mathrm{o}} \mathrm{de} \\
\text { cél./ml }\end{array}$ & Tempo & $\begin{array}{c}\mathrm{N}^{\mathrm{o}} \mathrm{de} \\
\text { cél./ml }\end{array}$ & Tempo & $\begin{array}{c}\mathrm{N}^{\mathrm{o}} \mathrm{de} \\
\text { cél./ml }\end{array}$ \\
\hline 1 & $2,6 \times 10^{10}$ & $0^{\prime} 31^{\prime \prime}$ & $2,0 \times 10^{9}$ & $23^{\prime} 45^{\prime}$ & 0 \\
\hline 2 & $1,7 \times 10^{6}$ & $0^{\prime} 40^{\prime}$ & 50 & $1^{\prime} 31^{\prime}$ & 0 \\
\hline 3 & $3,0 \times 10^{9}$ & $0^{\prime} 52^{\prime}$ & $5,0 \times 10^{8}$ & $20^{\prime} 07^{\prime}$ & 0 \\
\hline 4 & $1,2 \times 10^{7}$ & $0^{\prime} 35^{\prime}$ & $1,3 \times 10^{8}$ & $15^{\prime} 02^{\prime}$ & 0 \\
\hline $\mathrm{x}$ & $7,25 \times 10^{9}$ & $39^{\prime} 50^{\prime \prime}$ & $6,58 \times 10^{8}$ & $15^{\prime} 06^{\prime \prime}$ & 0 \\
\hline $\begin{array}{l}\text { Desvio } \\
\text { padrão }\end{array}$ & $1,26 \times 10^{10}$ & $9^{\prime} 11^{\prime \prime}$ & $9,20 \times 10^{8}$ & $9^{\prime} 44^{\prime \prime}$ & 0 \\
\hline \hline
\end{tabular}


VELANO, H. E.; NASCIMENTO, L. C. do; BARROS, L. M. de; PANZERI, H. Avaliação in vitro da atividade antibacteriana da água ozonizada frente ao Staphylococcus aureus. Pesqui Odontol Bras, v. 15, n. 1, p. 18-22, jan./mar. 2001.

que na primeira tomada da amostra no experimento 4, cujo tempo não excedeu a 35 segundos, houve um aumento virtual do número de bactérias (Tabela 2). Isto pode ser explicado levando-se em conta que a cultura utilizada estava na fase logarítmica de crescimento, com muitas bactérias em divisão e, assim, o ozônio, atuando na matriz intercelular bacteriana, promoveu a dispersão desses microrganismos. Além disso, as bactérias foram semeadas num meio de cultura sólido e, ao serem retiradas, muitas permaneciam agregadas, mesmo quando na forma de suspensão. Portanto, houve uma maior disseminação bacteriana, ocasionada pela desorganização da matriz por meio da ação do ozônio, que agiu de forma a dispersar os microrganismos, antes de atuar como um antimicrobiano (MINGUEZ ${ }^{17}, 1990$ ).

Comparando-se os resultados das Tabelas 1 e 2, foi verificado que, ao utilizar-se água previamente ozonizada, mesmo em suspensões contendo um elevado número de $\mathrm{UFC} / \mathrm{ml}$, obteve-se a inativação total, com tempos variando de 4 segundos a $5 \mathrm{mi}$ nutos e 25 segundos, enquanto na Tabela 2, para obter este resultado, foram necessários de 1 minuto e 31 segundos a 23 minutos e 45 segundos.
A partir dos dados obtidos nestes experimentos, é possivel sugerir que a água obtida após um período de 30 minutos de prévia ozonização, com residual de 0,6 mg/1 de ozônio inicial, seria de excelente padrão. Trabalhando-se deste modo, a formação do biofilme seria dificultada, melhorando a qualidade oferecida pelo serviço odontológico.

\section{CONCLUSÕES}

A análise dos resultados obtidos neste trabalho permite concluir que:

1. houve diferença no tempo de ação de desinfecção, quando se empregou água previamente tratada com ozônio e aquela não tratada previamente;

2. trabalhando-se com residual inicial de 0,6 mg/1 de ozônio dissolvido em água, após 30 minutos de fluxo constante, não foram obtidas culturas positivas de S. aureus nas condições dos experimentos;

3. é necessário padronizar a concentração desse gás para cada aplicação específica, na dependência das cepas bacterianas utilizadas, observando-se a relação tempo/concentração.

VELANO, H. E.; NASCIMENTO, L. C. do; BARROS, L. M. de; PANZERI, H. In vitro evaluation of the antibacterial activity of ozonized water against Staphylococcus aureus. Pesqui Odontol Bras, v. 15, n. 1, p. 18-22, jan./mar. 2001.

Staphylococcus aureus belongs to the normal flora of the skin, mucosa and nasopharynx of several animal species, including man, but it is also associated to illnesses such as abscesses, bacteremia, endocarditis and osteomyelitis, besides showing resistance to multiple drugs. The purpose of this paper was to evaluate the disinfecting ability of ozone when dissolved in water. Suspensions of Staphylococcus aureus with concentrations varying from $10^{6}$ to $10^{16}$ microorganisms $/ \mathrm{ml}$ were prepared. One milliliter of each recently prepared suspension was added to $99 \mathrm{ml}$ of distilled water (with or without previous ozonization) contained in a crystal reactor. Aliquots of $0.1 \mathrm{ml}$ of this new suspension were taken at various time intervals and, then, serially diluted and inoculated on plaques. The data indicated that there was difference in the disinfecting effect when distilled water was used with and without previous ozonization.

UNITERMS: Ozone; Staphylococcus aureus; Water; Disinfection.

\section{REFERÊNCIAS BIBLIOGRÁFICAS}

1. ATLAS, R. M.; WILLIAMS, J. F.; HUSTINGTON, M. K. Legionella contamination of dental-unit water. Appl Environ Microbiol, v. 61, n. 4, p. 1208-1213, 1995.

2. BECK, E. Ozone in preventive medicine. In: $12^{\text {th }}$ WORLD CONGRESS OF THE INTERNATIONAL OZONE ASSOCIATION, 3, Lille. Proceedings. p. 55-63, 1995.

3. BRAUNER, A. W. In vitro and clinical examination of the effect of ozone/oxygen gas mixture on impression materials on the oral microflora. In: $11^{\text {th }}$ WORLD CONGRESS OF OZONE, S. Francisco. Proceedings. 1993.

4. BROADWATER, W. T.; HOEHN, R. C.; KING, P. H. Sensitivity of three selected bacterial species to ozone. App1 Microbiol, v. 26, n. 3, p. 391-393, Sept. 1973.
5. COTTONE, J. A.; TEREZHALMY, G. T.; MOLINARI, J. A. Practical infection control in dentistry. 2. ed. Baltimore : Willians \& Wilkins, 1996. 437 p.

6. CRAWFORD, J. J. State-of-the-art: practical infection control in dentistry. J Amer Ass, v. 110, n. 4, p. 629-639, Apr. 1985.

7. DIAZ, S.; MENENDEZ, S.; ENG, L.; FERNANDEZ, I. No increase in sister chromatid exchanges and micronuclei frequencies in human limphocytes exposed to ozone in vitro. In: $12^{\text {th }}$ WORLD CONGRESS OF THE INTERNATIONAL OZONE ASSOCIATION, Lille. Proceedings. v. 3, p. 43-5, 1995.

8. DICKERMAN, J. M.; CASTRABERTE, A. O.; FULLER, J. E. Action of ozone on water-borne bacteria. J N Engl Water Works Assoc, v. 68, p. 11-15, 1954. 
VELANO, H. E.; NASCIMENTO, L. C. do; BARROS, L. M. de; PANZERI, H. Avaliação in vitro da atividade antibacteriana da água ozonizada frente ao Staphylococcus aureus. Pesqui Odontol Bras, v. 15, n. 1, p. 18-22, jan./mar. 2001.

9. DOMINGUE, E. L.; TYNDALL, R. L.; MAYBERRY, W. R.; PANCORBO, O. C. Effects of three oxidizing biocides on Legionella pneumophila serogroup 1. Appl Environ Microbiol, v. 54, n. 3, p. 741-747, Mar. 1988.

10. EDMUNDS, L. M.; RAWLINSON, A. The effect of cleaning on blood contamination in dental surgery following periodontal procedures. Aust Dent J, v. 43, n. 5, p. 349-353, 1998.

11. FETNER, R. H.; INGOLS, R. S. Bactericidal activity of ozone and chlorine against Escherichia coli at $1^{\circ} \mathrm{C}$. Advances in Chemistry Series, n. 212, p. 370-374, 1959.

12. GURLEY, B. Ozone: pharmaceutical sterilant of the future? Journal of Parenteral Science and Technology, v. 39, p. 256-261, 1985.

13. HAZELKORN, H. M.; BLOOM, B. E.; JOVANOVICH, B. D. Infection control in the dental office: has anything changed? J Am Dent Assoc, v. 27, p. 786-790, June 1996.

14. LEZCANO, I.; PÉREZ, R.; GUTIERREZ, M. et al. Inactivación com ozono de Streptococcus faecalis y Staphylococcus aureus, en agua, como modelo de bacterias gram (+). Symposium Internacional de Aplicaciones del Ozono, 2. Ciudad de La Habana, Cuba, 1997a.

15. LEZCANO, I.; PÉREZ, R.; SANCHES, E. et al. Inactivación com ozono de Pseudomonas aeruginosa y Escherichia coli, en agua, como modelo de bacterias gram (-). Sym- posium Internacional de Aplicaciones del Ozono, 2. Ciudad de La Habana, Cuba, 1997b.

16. MEURMAN, J. H.; PAJUKOSKY, H.; SNELLMAN, S. et al. Oral infections in home-living elderly patients admitted to an acute geriatric ward. J Dent Res, v. 76, n. 6, p. 1271-1276, 1997.

17. MINGUEZ. Actividad antimicrobiana del agua ozonizada en determinadas condiciones experimentales. Rev San Hig Pub, v. 64, p. 415-423, 1990.

18. NEIDLE, E. A.; YAGIELA, J. A. Farmacologia e terapêutica para dentistas. 3. ed. Rio de Janeiro : Guanabara Koogan, 1991, p. 483-499.

19. PREVOST, A. P.; ROBERT, M. C. R.; BARDEAU, J. Doctor, would you drink water from your dental unit? NY State Dent J, p. 22-28, 1995.

20. RODRIGUES, L. B.; CEPERO, M. S.; PERDOMO, E. O. Efectos del ozono en el tratamiento de la gingivoestomatitis herpética aguda. Rev Cubana Estomatol, v. 31, n. 1, p. 14-17, jan./jun. 1994.

21. VOSMAER, A. Ozone: its manufacture, properties and uses. New York: Van Nostrand Publisher, 1916.

22. WILliAMS, H. N.; KELLEY, J.; FOLINEO, D. et al. Assessing microbial contamination in clean water dental units and compliance with desinfection protocol. J Am Dent Assoc, v. 125, n. 9, p. 1205-1211, 1994.

23. WIMPEnNY, J. W. T. The validity of models. Adv Dent Res, v. 11, n. 1, p. 150-159, Apr. 1997.

Recebido para publicação em 10/02/00

Enviado para reformulação em 29/09/00

Aceito para publicação em 07/11/00 